\title{
Haemolytic Disease of the Fetus and Newborn: Past, Present and Future Considerations
}

\author{
Rounak Dubey ${ }^{1 *}$, Pragati Trigunait ${ }^{2}$, Amit Pawar ${ }^{3}$ and Arvind Kumar Yadav \\ ${ }^{1}$ Department of Transfusion Medicine and Blood Bank, AIIMS, Raipur, India \\ ${ }^{2}$ Department of Obstetrics and Gynecology, AIIMS, Raipur, India \\ ${ }^{3}$ Armed Forces Transfusion Centre, New Delhi, India \\ ${ }^{4}$ Department of Transfusion Medicine, Command Hospital, Chandigarh, India \\ *Corresponding Author: Rounak Dubey, Department of Transfusion Medicine and Blood Bank, AIIMS, Raipur, Chhattisgarh, India.
}

Received: August 28, 2019; Published: September 30, 2019

DOI:_10.31080/ASMS.2019.03.0425

\begin{abstract}
The complex etiology, pathogenesis and management of Hemolytic disease of the fetus and newborn (immune mediated) has drawn keen interest of not only the obstetricians and pediatricians worldwide but has also fascinated immohematologists over decades. Our understanding of this disease has evolved significantly in the recent past and as we usher into the era of precision medicine and molecular testing, the incidence of HDFN has remarkably reduced, especially in the developed countries. It still remains a cause of concern in the developing countries, where it is most commonly associated with Rh ' $\mathrm{D}$ ' negative ante-natal cases. There are multiple factors involved in the pathogenesis of the disease which warrant different diagnostic approaches as well as treatment protocols as per the severity of the disease. In addition to prophylactic administration of Anti-D immunoglobulin, genotype testing will pave the way for future guidelines. With due consideration on cases with specific requirement for molecular testing, a cost-effective approach may be implemented.
\end{abstract}

Keywords: Hemolytic Disease of Fetus and Newborn; Alloimmunization; Rh Negative Pregnancy; RhIG; Intra Uterine transfusion

\section{Abbreviations}

HDFN: Hemolytic Disease of Fetus and Newborn; DAT: Direct Antiglobulin Test; IAT: Indirect Antiglobulin Test; TPH: Trans Placental Haemorrhage; AHG: Anti Human Globulin

\section{Introduction}

History of HDFN

Hemolytic disease of the newborn was first reported by a French midwife in a set of twins in 1609 [1]. The relationship between fetal hydrops and triad of jaundice, anemia and erythroblasts in the circulation was described by Diamond and colleagues in 1932 . This condition was later described as erythroblastosis fetalis [2]. It's exact cause was determined by Levine after discovery of the $\mathrm{Rh}$ blood group system in 1940. The pathogenesis of Rh allo-immunization was confirmed in 1953 by Chown and coworkers [3]. and it was found to be the result of passage of Rh positive fetal RBCs after trans-placental hemorrhage into the maternal circulation.

In 1966, a combined study was carried out by two groups from the United States and United Kingdom in which they demonstrated that anti-D IgG prophylaxis soon after delivery prevented sensitization in Rh negative women [4]. In 1971 world health organization technical report recommended that a dose of $25 \mu \mathrm{g}$ of anti-D IgG should be given intramuscularly for every $1 \mathrm{ml}$ of feto-maternal hemorrhage. This recommendation was further reinforced in 1998 by the American Association of Blood Banks and American College of Obstetricians and Gynecologists. Prophylaxis at 28 weeks of gestation was also recommended. The incidence of Rh alloimmunization has declined significantly due to routine use of IgG prophylaxis. The perinatal effects of $\mathrm{Rh} \mathrm{D}$ alloimmunization are referred as hemolytic disease of the fetus and newborn. Fetal manifestations of this condition are better appreciated with advancements like cordocentesis and fetal ultrasonography.

Our understanding about the pathogenesis, prevention and treatment of HDFN has evolved significantly since the time it was first reported. However, to the present day, researchers and clinicians are working to improve the diagnostic and therapeutic modalities associated with this disease. The most common cause of HDFN has been identified as anti-D antibody, even though its incidence has declined considerably with IgG prophylaxis. The role of other antibodies and their prevalence has been more evident in the Western countries compared to the Indian population [5]. Mother's serum can be used not only for identification of the antibodies but also its semi-quantification by titration.

\section{Incidence and prevalence}

The exact burden of HDFN is hard to estimate in view of limited reporting of the disease and most of the times, blood groups other than $\mathrm{Rh}$ and $\mathrm{ABO}$, often go undetected. One of the recent studies in 2016 estimated that around 1/300 - 1/600 live births are affected by maternal RBC alloimmunization [6] and the prevalence of $\mathrm{Rh}$ disease is estimated to be 276 per 100,000 live birth in developing countries. In comparison, the prevalence of $\mathrm{Rh}$ disease in de- 
veloped countries has been reduced to 2.5 per 100,000 live births, which can be attributed to higher-quality perinatal-neonatal care [7].

\section{Status in developed countries}

The spectrum of HDFN has undergone an overwhelming change during the past 30 to 40 years. HDFN used to be a common neonatal problem in 1960s and early 1970s. With the introduction of post-partum prophylactic Rh immunoglobulin (RhIG or anti-D) to D-negative women in 1970, the scenario has undergone a radical change [8]. With improving health care system, the incidence of alloimmunization has reduced by more than $90 \%$ in developed countries.

\section{Status in countries with low human development index}

In countries with a low human development index, neonatal surveillance and therapy are still in preliminary stages. Antepartum care and screening are also very limited and restricted to certain areas. HDFN is, therefore, still a major cause of morbidity and mortality in these countries. Prevalence of alloimmunization varies in different populations as seen in various studies worldwide, has been summarized in table 1.

\begin{tabular}{|c|c|c|c|c|c|}
\hline S. No & Study done by & Country & Year & $\begin{array}{c}\text { Sample } \\
\text { size }\end{array}$ & $\begin{array}{c}\text { Preva- } \\
\text { lence }\end{array}$ \\
\hline 1 & Filbey., et al. [9] & Sweden & 1995 & 11350 & 0.57 \\
\hline 2 & $\begin{array}{c}\text { Howard., et al. } \\
{[10]}\end{array}$ & UK & 1998 & 22264 & 1.0 \\
\hline 3 & $\begin{array}{l}\text { Chandrashek- } \\
\text { har., et al. [11] }\end{array}$ & Ireland & 2001 & 34913 & 0.53 \\
\hline 4 & Lee., et al. [12] & China & 2003 & 28303 & 0.79 \\
\hline 5 & $\begin{array}{c}\text { Gottvall., et al. } \\
\text { [13] }\end{array}$ & Sweden & 2008 & 78145 & 0.4 \\
\hline 6 & $\begin{array}{l}\text { Al-Ibrahim., et } \\
\text { al. [14] }\end{array}$ & $\begin{array}{l}\text { Saudi } \\
\text { Arabia }\end{array}$ & 2008 & 1195 & 1.92 \\
\hline 7 & $\begin{array}{c}\text { Pahuja., et al. } \\
\text { [15] }\end{array}$ & India & 2011 & 3577 & 1.25 \\
\hline
\end{tabular}

Table 1: Prevalence of alloimmunization in antenatal cases in different countries.

\begin{tabular}{|c|c|c|}
\hline S. No & $\begin{array}{l}\text { Blood group } \\
\text { System }\end{array}$ & Antibodies Detected \\
\hline 1 & The Rh system & $\begin{array}{c}\text { anti-D, -c, -C, }-C^{w},-C^{\mathrm{X}},-\mathrm{e},-\mathrm{E},-\mathrm{E}^{\mathrm{w}},-\mathrm{ce}, \\
-\mathrm{Ce}^{\mathrm{s}}, \mathrm{Rh} 29,-\mathrm{Rh} 32,-\mathrm{Go}^{\mathrm{a}},-\mathrm{Be}^{\mathrm{a}},- \text { Evans, } \\
\text {-Riv }\end{array}$ \\
\hline 2 & The Kell system & $\begin{array}{c}\text { anti-K, }-\mathrm{k},-\mathrm{Ku},-\mathrm{Kp}^{\mathrm{a}},-\mathrm{Kp}^{\mathrm{b}},-\mathrm{J} \mathrm{s}^{\mathrm{a}} \text { and } \\
-\mathrm{Js}^{\mathrm{b}}\end{array}$ \\
\hline 3 & The Kidd system & anti-Jk, $\mathrm{a}^{\mathrm{a}}-\mathrm{Jk} \mathrm{k}^{\mathrm{b}}$ and $-\mathrm{Jk} 3$ \\
\hline 4 & The Duffy system & anti-Fy and - Fy3 \\
\hline 5 & The MNSs system & $\begin{array}{c}\text { anti-M, '-N', -S, -s, -U, -Vw, -Far, -M"', } \\
\text {-Mit, -Mur, -Hil, -Hut and -En' }\end{array}$ \\
\hline 6 & Other systems & 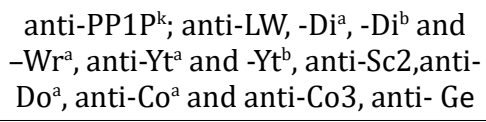 \\
\hline 7 & $\begin{array}{l}\text { Low-frequency } \\
\text { antigens }\end{array}$ & anti - Bi, By, Fra, Good, Rd, Re', Zd \\
\hline 8 & $\begin{array}{l}\text { High-frequency } \\
\text { antigens }\end{array}$ & anti - Jra and Lan \\
\hline
\end{tabular}

Table 2: The list of antibodies that have caused HDFN

\section{Pathophysiology}

Transfer of antibodies from mother to fetus

The transfer of antibodies from mother to fetus takes place via the placenta in humans. The immunoglobulins transferred via placenta are IgG type. It is bound to an Fc receptor (FcRn) and transported by the same. FcRn is structurally different from other Fc receptors. It is a distant member of the MHC class I protein family and is dependent for function on dimerization with $\beta 2$ macroglobulin. The $\alpha 2$ and $\beta 2$ macroglobulin domains of FcRn interact with the $\mathrm{C} \gamma 2$ and $\mathrm{C} \gamma 3$ domains of the IgG molecule [16]. The function of FcRn is not only to transfer IgG from mother to fetus to provide passive protective immunity, but also to protect IgG from normal serum protein catabolism [17]. As a consequence, the half-life of IgG is considerably longer than other immunoglobulins (22 - 23 days in humans). In addition to the ABO blood group system, various antibodies belonging to different blood groups systems have been implicated [18] in the development of HDFN in the past (Table 2). Amongst these, the antibodies to the Rh and Kell blood group system are more commonly observed while some blood group systems, like Lewis, are not known to cause HDFN.

In Rh(D) HDFN, the Rh-positive first born child of a Rh-negative mother is usually unaffected because the mother has not yet been sensitized. Maximum fetal RBCs enter the maternal circulation at the time of delivery, when the placenta separates from the uterus. If $D$ antigen is inherited from the father, the fetal cells carrying $D$ antigen immunize the mother and stimulate the production of anti-D. Once the mother is immunized to $\mathrm{D}$ antigen, all subsequent pregnancies where the fetes inherits the $D$ antigen, will be affected. The sensitized RBCs are haemolyzed by the fetal monocyte-macrophage system, which results in anaemia. There are several factors which may affect immunization and severity of HDFN. It includes host factors, antigenic exposure, class of immunoglobulin, specificity of antibody and influence of the $\mathrm{ABO}$ group.

Feto-maternal haemorrhage (FMH) during pregnancy can cause substantial rise in maternal antibody titters, and lead to increased severity of HDFN. By using the acid elution method for detecting fetal haemoglobin, it has been estimated that trans-placental haemorrhage of fetal red blood cells into the maternal circulation occurs in up to $7 \%$ of women during pregnancy [19]. The risk of fetomaternal haemorrhage further increases with interventions like amniocentesis, chorionic villus sampling and trauma to the abdomen. In most of the cases, the volume of FMH is small, but even $0.1 \mathrm{~mL}$ of fetal RBCs can immunize the mother [20].

\section{Hemolysis, anemia and development of erythroblastosis fetalis}

Haemolysis of fetal RBCs occurs when maternal IgG attaches to specific antigens of the fetal RBCs. These antibodies coated cells are removed from the circulation by the macrophages of the spleen. The rate of haemolysis of RBCs depends upon the titer of antibody, specificity and number of antigenic sites on the fetal RBCs. Lysis of fetal RBCs and the subsequent anaemia stimulate the fetal bone marrow to accelerate the production of RBCs. This accelerated production of RBCs results in release of immature RBCs (erythroblasts) into the circulation. This phenomenon is called as erythroblastosis fetalis. 


\section{Hepatic involvement and development of hydrops fetalis}

When the fetal bone marrow is unable to produce sufficient RBCs to compensate the ongoing RBC destruction, erythropoiesis outside the bone marrow is increased, mainly in the hematopoietic tissues of the spleen and liver. These organs become enlarged (hepatosplenomegaly), which further leads to portal hypertension and hepatocellular damage. There is decreased hepatic production of plasma proteins which causes hypo-proteinemia. Severe anemia and hypo-proteinemia further leads to the development of highoutput cardiac failure with generalized edema, pleural and pericardial effusions and ascites. This condition is called as hydrops fetalis [20]. The Pathophysiology of fetal hydrops can be described by following major events:

1. Decreased hepatic production of plasma proteins

2. Increased volume overload

3. Cardiac decompensation

4. Decreased oncotic pressure

5. Increased capillary permeability

\section{Perinatal effects}

The process of RBC destruction continues even after the infant is delivered alive. It may continue as long as maternal antibody persists in the new-born infant's circulation. The rate of RBC destruction after birth decreases because no additional maternal antibody is entering the infant's circulation through the placenta. However, IgG is distributed both extravascular and intravascularly and has a half-life of 25 days, so antibody binding and haemolysis of RBCs continue for several days to weeks after delivery.

The levels of total bilirubin in the fetal circulation and amniotic fluid may be elevated, but the fetes usually remains unaffected as it is cleared through maternal circulation. After birth, accumulation of metabolic by-products of RBC destruction can become a severe problem for the new-born infant. The new-born liver is unable to conjugate bilirubin efficiently, especially in premature infants. With moderate to severe haemolysis, the unconjugated, or indirect, bilirubin can reach levels toxic to the infant's brain (generally, more than 18 to $20 \mathrm{mg} / \mathrm{dL}$ ) and if left untreated can cause kernicterus or permanent damage to parts of the brain.

Factors influencing the severity of HDFN

Size of Feto-maternal haemorrhage

The amount of fetal red cells that cross the placenta into maternal circulation in the third trimester of pregnancy is usually small and insufficient to cause antibody production. At delivery, a trans placental hemorrhage is very common. The amount of fetal blood entering the maternal circulation varies from less than $1 \mathrm{ml}$ to 10 $\mathrm{ml}$ or more [21]. The risk of feto-maternal hemorrhage further increases with interventions like amniocentesis, chorionic villus sampling and trauma to the abdomen. At the time of delivery, the incidence of FMH is more than $50 \%$ [22].
Parity

The First pregnancy usually remains unaffected and the chances of alloimmunization increase with each pregnancy. About $70 \%$ cases are confronted with HDN in second and third pregnancy. Also, the titres appear to rise much earlier with subsequent pregnancies, compared to first or second pregnancy.

\section{Effect of $\mathrm{ABO}$ incompatibility between mother and the fetus}

ABO incompatibility between mother and fetus provides some protection to the fetus from Rh-HDN. The proposed mechanism is that the existing maternal ABO allo-antibodies destroy the $\mathrm{Rh}(\mathrm{D})$ positive fetal red cells immediately as they enter the maternal circulation before they can sensitize the mother.

\section{Zygosity of father}

If the father is heterozygous for the implicated antibody there is $50 \%$ chance of the child being affected by Rh-HDN. It is not possible to determine the genotype of the father for Rh (D) antigen with certainty unless the father has a living D- negative child. However, for C and $\mathrm{E}$ antigens true genotype can be determined.

\section{History of blood transfusion}

A $\mathrm{Rh}(\mathrm{D})$ negative mother who has been immunized by $\mathrm{Rh}(\mathrm{D})$ positive blood transfusion has a risk of delivering a baby with RhHDN even in the first pregnancy. The risk of immunization is greater with $\mathrm{Rh}(\mathrm{D})$ positive blood transfusion than with $\mathrm{Rh}(\mathrm{D})$ positive pregnancy in a woman since the antigens load is much greater in transfusion.

\section{History of miscarriage or MTP}

Any incidence of miscarriage exposes the mother to fetal RBCs and increases the risk for alloimmunization. As a result, the subsequent pregnancies maybe exposed to pre-formed circulating antibodies.

\section{Association of HDFN with Rh blood group system}

Of all the blood group systems associated with HDFN, the Rh Blood Group system is of utmost significance, especially in context of a developing country. Though ABO blood group system is the most common cause of HDFN, it rarely causes a severe HDFN. The most common cause of HDN which is severe enough to require treatment is incompatibility of the Rh system and in $95 \%$ of these cases the D antigen is responsible [23]. Other antigens of Rh system; c, C and $\mathrm{E}$ have been occasionally implicated, mostly in combination with the $\mathrm{D}$ antigen. Other Blood Group System antigens like Kell, Kidd and Duffy are rarely involved.

\section{Diagnosis of HDFN}

The diagnosis and management of HDFN requires collective effort and collaboration of obstetrician and the personnel of the clinical laboratory performing the serologic testing. Serologic and clini- 
cal tests performed at appropriate times during the pregnancy can accurately determine the level of antibody in the maternal circulation, the potential of the antibody to cause HDFN, and the severity of RBC destruction during gestation.

\section{Detailed history}

The pregnant woman must be asked about previous pregnancies, their outcomes and prior transfusions. Previous severe disease and poor outcome predict similar findings in the current pregnancy.

\section{Serologic testing of the mother}

The recommended obstetric practice is to perform the type and antibody screen at the first prenatal visit, preferably during the first trimester [24]. Although antibody titters are useful in assessing the extent of intrauterine fetal anaemia during the first affected pregnancy, antibody titters are less predictive in subsequent pregnancies. Apart from first antenatal visit, Rh (D) negative mothers should also be screened at $28^{\text {th }}$ week of pregnancy.

\section{$\mathrm{ABO}, \mathrm{Rh}$ and antibody screen}

The prenatal specimen must be typed for $\mathrm{ABO}$ and $\mathrm{Rh}$. The antibody screening method must be able to detect clinically significant IgG alloantibodies that are reactive at $37^{\circ} \mathrm{C}$ and in the antiglobulin phase. At least two separate reagent screening cells, covering all common blood group antigens (preferably homozygous), should be used. For tube testing, an antibody-enhancing medium such as polyethylene glycol (PEG) LISS can increase sensitivity of the assay [18]. There are commercial RBC panels also available for the same (Figure 1).

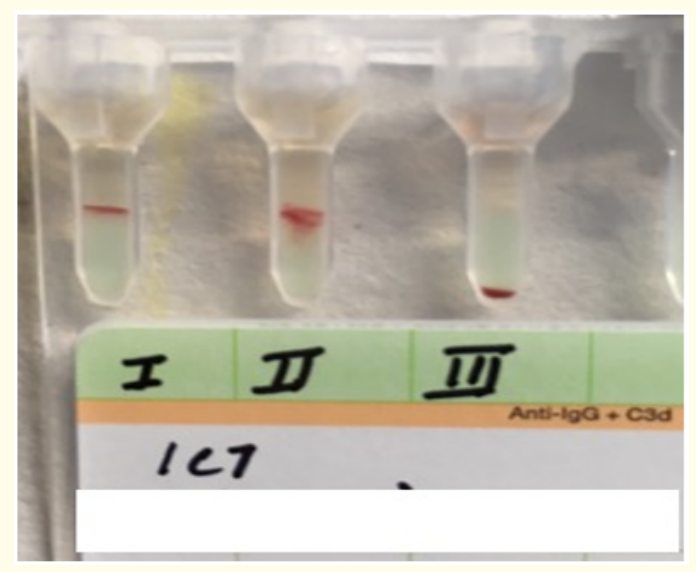

Figure 1: Result of antibody screening panel using polyspecific Coombs card.

Prenatal patients may produce clinically insignificant antibodies, such as anti-Lea or anti-Leb. Therefore, immediate spin and room temperature incubation phases are omitted, and anti-IgG rather than polysemic antiglobulin reagent is used. These steps reduce detection of IgM antibodies, which cannot cross the placenta. Other antibody screening methods, such a solid phase or gel column, may be used. If the antibody screen is nonreactive, repeat testing is recommended before RhIG therapy in Rh-negative prenatal patients and in the third trimester if the patient has been transfused or has a history of unexpected antibodies. If antibody(ies) is/ are detected at any stage then the following should be done [23]:

1. Repeat titer every month: Severity of the disease is generally, though not always, correlated with the titer of the antibodies. A titer of 1:16 or above and a rising titer at repeated testing is significant and is an indication for amniocentesis.

2. Identify the antibody(ies)

3. Carry out Rh phenotype to confirm the implicated antibody.

\section{Antibody identification}

If the antibody screen is reactive, the antibody identity must be determined. Follow-up testing will depend on the antibody specificity. Cold reactive IgM antibodies such as anti-I, anti-IH, anti-Lea, anti-Leb and anti-P1 can be ignored. Lewis system antibodies are rather common in pregnant women but have not been reported to cause HDFN.

Many Rh-negative pregnant women have weakly reactive anti-D, particularly during the third trimester. Most of these women have received RhIG, either after an event with increased risk of geomaterial haemorrhage or at 28 weeks' gestation (antenatal). The passively administered anti-D will be weakly reactive in testing and will remain demonstrable for 2 months or longer. This must be distinguished from active immunization. A titer higher than 4 (by tube method) almost always indicates active immunization; with a titer under 4, active immunization cannot be ruled out, but it is less likely [18].

If the antibody specificity is determined to be clinically significant and the antibody is IgG, further testing is required. Other than anti-D, the most common and most significant antibodies are anti$\mathrm{K}$, anti-E, anti-c, anti-C, and anti-Fya. There are commercially available RBC test panels/kits available (Figure 2 and 3) for antibody identification, while some laboratories use in-house prepared panels for the same.

\section{Antibody titres}

The relative concentration of all antibodies capable of crossing the placenta and causing HDFN is determined by antibody titration. The patient serum or plasma is serially diluted and tested against appropriate RBCs to determine the highest dilution at which a reaction occurs [25]. The method must include the indirect antiglobulin phase using anti-IgG reagent. The result is expressed as either the reciprocal of the titration endpoint or as a titter score. 


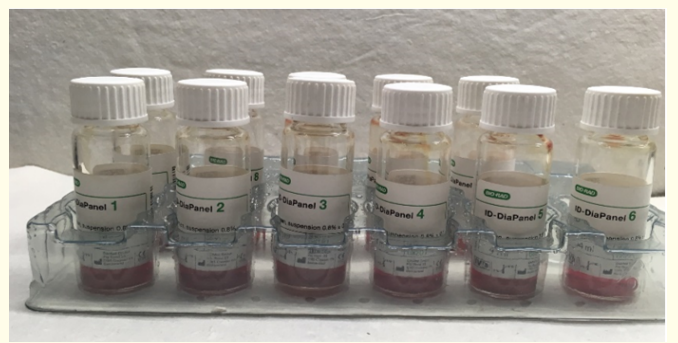

Figure 2: Commercial (11 Cell) Antibody Identification Panel (Reagent Cells).

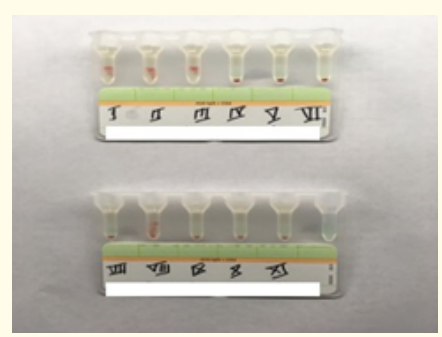

Figure 3: Result of antibody Identification panel using polyspecific coombs card.

The method chosen is critical for the appropriate clinical correlation. Methods using enhancing media or gel column result in higher titres [26], therefore the critical titer level for these other methods must be determined by reviewing the outcome of several pregnancies complicated by HDFN.

For the recommended method of conventional tube testing using normal saline (Figure 4), 16 is considered the critical titter. If the initial titter is 16 or higher, a second titer should be done at about 18 to 20 weeks' gestation. A titer reproducibly and repeatedly at 32 or above is an indication for colour Doppler imaging to assess middle cerebral artery peak systolic velocity (MCA - PSV) after 16 weeks' gestation. When the titer is less than 32 , it should be repeated at 4 - week intervals, beginning at 16 to 20 weeks' gestation and then every 2 to 4 weeks during the third trimester [18].

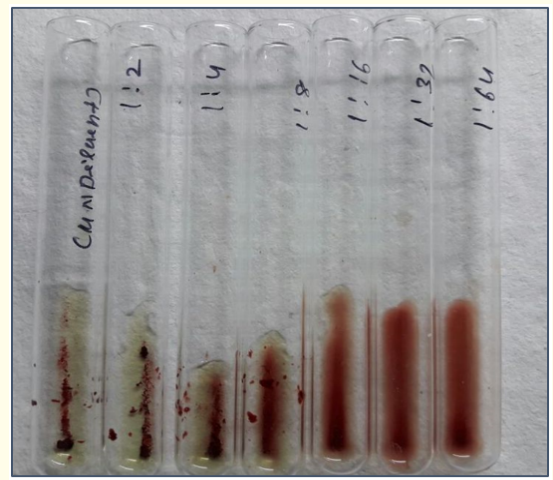

Figure 4: Titration by tube testing using Normal Saline and AHG.
Antibody titer alone cannot predict severity of HDFN. In some sensitized women, the antibody titer can remain moderately high throughout pregnancy while the fetes is becoming more severely affected. Similarly, a previously sensitized woman can have consistently high antibody titer whether pregnant or not, and whether the fetes is Rh-positive or Rh negative. In others, the titer can rise rapidly, which signifies increasing severity of HDFN [24]. However, antibody titers consistently below the laboratory's critical titer throughout the pregnancy reliably predict an unaffected or mild-to moderately affected fetus, with the exception of anti-K with a Kpositive fetus. Titration studies at time of delivery are not recommended, because they provide no clinically useful information.

\section{Paternal phenotype and genotype}

A specimen of the father's blood should be obtained and tested for the presence and zygosity of the corresponding antigen. If the mother has anti-D and the father is D-positive, a complete $\mathrm{Rh}$ phenotype can help determine his chance of being homozygous or heterozygous for the $\mathrm{D}$ antigen. The information is helpful in determining further testing of the mother and in counselling her about potential treatment plans and complications of HDFN. In cases of antibody specificity other than $\mathrm{D}$, testing the father can save time and expense if he is shown to lack the corresponding antigen.

\section{Colour doppler middle cerebral artery peak systolic velocity}

At about 16 to 20 weeks' gestation, further diagnosis and treatment are begun. Patients with a history of a severely affected fetus or early fetal death may require earlier intervention. The measurement of the fetal middle cerebral artery peak systolic velocity (MCA-PSV) with colour Doppler ultrasonography can reliably predict anaemia in the fetus. Colour Doppler indicates the direction of blood flow, using red for arterial flow and blue for venous. The middle cerebral artery is used because of its easy accessibility. The measurement is based on the reduced blood viscosity at low haematocrit and the resulting faster velocity [27]. The peak systolic (arterial) velocity is plotted on a standardized graph to determine the critical point for cordocentesis. MCA-PSV is non-invasive and poses no adverse effects for the fetus [27]. The critical value for IUT is usually taken to be that exceeding 1.5 Multiples of the Median for that gestational age.

\section{Cordocentesis}

Advanced sonography allows clinicians to obtain a sample of fetal blood through a procedure called cordocentesis. Using highresolution ultrasound with colour Doppler enhancement of blood flow, the umbilical vein is visualized at the level of the cord insertion into the placenta. A spinal needle is inserted into the umbilical vein, and a sample of the fetal blood is obtained. The fetal blood sample can then be tested for haemoglobin, haematocrit, bilirubin, blood type, direct antiglobulin test (DAT), and antigen phenotype and genotype. As it is an invasive procedure and can pose risk to the foetus, this procedure is rarely performed these days. 


\section{Amniocentesis}

For management of HDFN, amniocentesis is uncommonly used, because MCA-PSV is non-invasive and gives the same information. The concentration of bilirubin pigment in the amniotic fluid estimates the extent of fetal haemolysis. The amniotic fluid is tested by a spectrophotometric scan at steadily increasing wavelengths, so the change in the optical density $(\Delta \mathrm{OD}$ ) at $450 \mathrm{~nm}$ (the absorbance of bilirubin) can be calculated. The measurement is plotted on a graph according to gestational age. An increasing or unchanging $\triangle \mathrm{OD} 450 \mathrm{~nm}$ as pregnancy proceeds predicts worsening of the fetal haemolytic disease and the need for frequent monitoring and intervention if indicated. High values indicate severe and often lifethreatening haemolysis (fetal haemoglobin less than $8 \mathrm{~g} / \mathrm{dL}$ ) and require urgent intervention.

A chart was prepared by Liley in 1961 to indicate the approximate severity of disease for a particular OD450 at any stage of pregnancy from 27 weeks onwards. The chart is divided into 3 Zones (Figure 5), indicating the approximate severity of haemolytic disease, from readings of the OD450 of amniotic fluid. Zone 1 indicates a mildly affected or unaffected infant, whereas zone 3 indicates a high probability of hydrops and fetal death; the significance of zone 2 is intermediate.

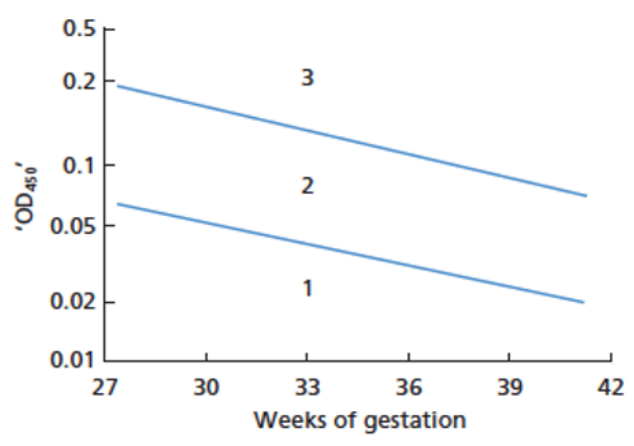

Figure 5: Liley's three zones, indicating the approximate severity of haemolytic disease.

\section{Serologic testing of the newborn infant}

Serologic testing of the cord blood is used to confirm HDFN and prepare for possible transfusion.

\section{ABO Grouping}

ABO antigens are not fully developed in new-born infants, so new-borns may show weaker reactions than older children and adults. In addition, infants do not have their own isoagglutinin, but may have those of the mother, so reverse grouping cannot be used to confirm the $\mathrm{ABO}$ group.

\section{Rh Typing}

Rarely, the infant's RBCs can be heavily antibody-bound with maternal anti-D, causing a false-negative Rh type, or what has been called blocked Rh. An eluate from these RBCs will reveal anti-D, and typing of the eluted RBCs will show reaction with anti-D.

\section{Direct antiglobulin test}

The most important serologic test for diagnosing HDFN is the DAT with anti-IgG reagent. A positive test result indicates that the antibody is coating the infant's RBCs; however, the strength of the reaction does not correlate well with the severity of the HDFN. A positive test result may be found in infants without clinical or other laboratory evidence of haemolysis (e.g., mother received RhIG).

\section{Elution}

The routine preparation of an eluate of all infants with a positive DAT result is unnecessary. Elution in cases of known HDFN and postnatal $\mathrm{ABO}$ incompatibility is not needed, because eluate results do not change therapy. The preparation of an eluate may be helpful when the cause of HDFN is in question. As noted earlier, the resolution of a case of blocked $\mathrm{Rh}$ requires an eluate.

\section{Determination of $D$ group of fetus in utero}

The D group of the fetus can be determined prenatally, by polymerase chain reaction (PCR) amplification of that region of fetal DNA encoding RHD. Fetal DNA for this purpose can be obtained from amniotic fibroblasts. Only $1-2 \mathrm{ml}$ of amniotic fluid is needed and can be obtained late in the first trimester or early in the second The test can also be done on a chorionic villus sample but this carries greater risks for the fetes and is also a cause of TPH (Bennett., et al. 1993)

The preferred method utilizes fetal DNA present in maternal plasma, as this poses no risk to the pregnancy or of TPH and thereby the possibility of sensitizing the mother to fetal antigens. Maternal plasma contains about $3 \%$ fetal DNA in the first trimester rising to $6 \%$ in the third trimester. The method can be undertaken from the beginning of the second trimester (Lo., et al. 1998). A multiplex PCR based on exon 4 and exon 7 has been used for routine diagnostic purposes. The $\mathrm{D}$ group of a fetes can also be determined using real-time PCR and this is the method preferred by most laboratories. This method requires two sequence-specific oligonucleotide primers to amplify the region of interest and a third oligonucleotide (probe) that anneals to a region within the amplicon. The probe has fluorescent dyes attached at its $5^{\prime}$-end (reporter dye) and its $3^{\prime}$-end (quencher dye). The method is extremely sensitive and, provided the PCR is designed to take account of common forms of D-negative phenotype where RHD is not completely absent such as the pseudo RHD and RHD-CE-Ds, can be used to provide a very effective diagnostic service [25]. 
Antenatal treatment of hemolytic disease

Plasma exchange in the mother

Plasma exchange has a very limited application in treatment of HDFN because deaths in utero from haemolytic disease usually do not occur before about 17 weeks, and i.e. transfusion becomes possible as early as the eighteenth week of gestation. It has been suggested that plasma exchange should be reserved for the woman with a previous history of hydrops developing before 24 - 26 weeks' gestation, with a homozygous (DD) partner. Intensive plasma exchange should then be begun at $10-12$ weeks, with fetal blood sampling at $19-22$ weeks [22].

\section{IVIG given to mother}

A single course totalling $2 \mathrm{~g} / \mathrm{kg}$ over 5 days or repeated weekly injections of $1 \mathrm{~g} / \mathrm{kg}$ have been tried in conjunction with plasma exchange or with intravascular transfusion of the fetes with mixed results (Rubo and Wahn 1990; Chitkara., et al. 1990). IVIG might act by saturating FcRn and thereby inhibiting placental transfer of anti-D to the fetus. In a study by Ruma., et al. (2007), seven alloimmunized cases with a history of perinatal loss and two with markedly elevated maternal antibody titres, were given serial plasmapheresis followed by weekly infusions of intravenous Ig. This resulted in reduced maternal red cell antibody titres. Serial peak middle cerebral artery velocities remained below the threshold for moderate to severe fetal anaemia during therapy and all seven infants survived.

\section{Intrauterine transfusion}

Intervention in the form of intrauterine transfusion becomes necessary when one or more of the following conditions exists:

1. MCA-PSV indicates anemia.

2. Fetal hydrops is noted on ultrasound examination.

3. Cordocentesis blood sample has hemoglobin level less than $10 \mathrm{~g} / \mathrm{dL}$.

4. Amniotic fluid $\Delta$ OD $450 \mathrm{~nm}$ results are high.

Intrauterine transfusion is usually performed by accessing the fetal umbilical vein (cordocentesis) and injecting donor RBCs directly into the vein (Figure 6). The goal of intrauterine transfusion is to maintain fetal haemoglobin above $10 \mathrm{~g} / \mathrm{dL}$. Once intrauterine transfusion is initiated, the procedure is repeated every 2 to 4 weeks until delivery. The initial intrauterine transfusion is rarely performed after 36 weeks' gestation. Intrauterine transfusion apparently suppresses the fetal bone marrow RBC production. During the first weeks after birth, the infant may require additional RBC transfusion.

\section{Postnatal treatment of hemolytic disease \\ Phototherapy}

After delivery, the neonate can develop hyperbilirubinemia of unconjugated bilirubin. Phototherapy at 460 to $490 \mathrm{~nm}$ is used to

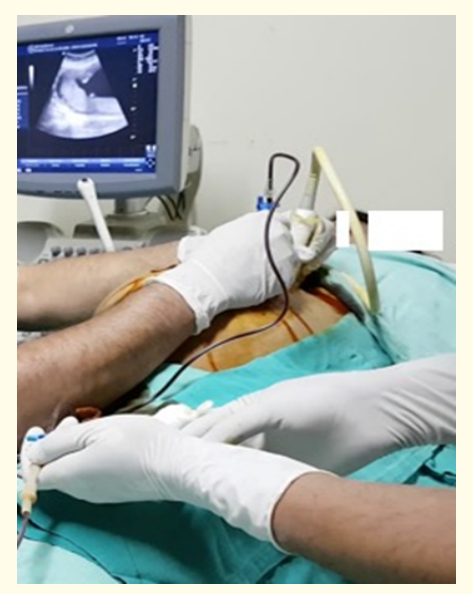

Figure 6: IUT being performed under USG guidance.

change the unconjugated bilirubin to isomers, which are less lipophilic and less toxic to the brain. Relatively high doses are given by using two banks of lights to surround the infant's body. In infants with mild-to-moderate haemolysis or history of intrauterine transfusion, phototherapy is generally sufficient.

\section{Intravenous immune globulin}

Intravenous immune globulin (IVIG) is increasingly used to treat hyperbilirubinemia of the new-born caused by HDFN. The IVIG competes with the mother's antibodies for the Fc receptors on the macrophages in the infant's spleen, reducing the amount of haemolysis.

\section{Exchange transfusion}

Exchange transfusion is the use of whole blood or equivalent to replace the neonate's circulating blood. Exchange transfusion is rarely required because of advances in phototherapy and the use of IVIG. In addition, less than one-half of the cases of HDFN are caused by anti-D, so the majority is generally less severe. Exchange transfusions are used primarily to remove high levels of unconjugated bilirubin and thus prevent kernicterus. Premature new-borns are more likely than full-term infants to require exchange transfusions for elevated bilirubin because their livers are less able to conjugate bilirubin. Other advantages of exchange transfusion include the removal of part of the circulating maternal antibody, removal of sensitized RBCs, and replacement of incompatible RBCs with compatible RBCs; all of these helps interrupt the bilirubin production caused by haemolysis.

Traditional guidelines suggest that exchange transfusion in HDN is required for:

- Severe anaemia: $\mathrm{Hb}<10 \mathrm{~g} / \mathrm{dl}$ at birth (with the possible exception of anti-Kell, which, as outlined above, can cause considerable anaemia without appreciable hyperbilirubinemia); and/or 
- $\quad$ Severe hyperbilirubinemia (total serum bilirubin $>350$ $\mu \mathrm{mol} / \mathrm{l}$ ) in the first $48 \mathrm{~h}$ of life or rapidly increasing hyperbilirubinemia (total serum bilirubin increasing $>10 \mu \mathrm{mol} / \mathrm{l}$ per hour).

\section{RhIG}

Active immunization induced by RBC antigen can be prevented by the concurrent administration of the corresponding RBC antibody. This principle has been used to prevent immunization to D antigen by the use of high-titer RhIG. During pregnancy and delivery, fetal and maternal blood are mixed. If the mother is $\mathrm{Rh}$ negative and the fetes is $\mathrm{Rh}$ positive, the mother has up to a $16 \%$ chance of being stimulated to form anti-D. As little as $1 \mathrm{~mL}$ of fetal RBCs can elicit a response. Before delivery, the risk of sensitization is $1.5 \%$ to $1.9 \%$ in susceptible women, indicating that a significant amount of fetal RBCs can enter the maternal circulation during pregnancy. However, the greatest risk of immunization to $\mathrm{Rh}$ is at delivery.

\section{Indications}

Antenatal

Because of the known risk of Rh immunization during pregnancy, RhIG should be given early in the third trimester or at about 28 weeks' gestation. The dose does not pose a risk to the fetes, as this amount will cause a titer of only 1 or 2 in the mother. However, a positive DAT result may be observed in the new-born.

\section{Postpartum}

The Rh-negative nonimmunized mother should receive RhIG soon after delivery of a Rh-positive infant. Based on experiments conducted many years ago, the recommended interval is within 72 hours after delivery. Even if more than 72 hours have elapsed, RhIG should still be given, as it may be effective and is not contraindicated.

Dose and administration of RhIG

The regular-dose vial of RhIG contains sufficient anti-D to protect against $15 \mathrm{~mL}$ of packed RBCs or $30 \mathrm{~mL}$ of whole blood. This is equal to $300 \mu \mathrm{g}$ of the World Health Organization (WHO) reference material. In some countries like the United Kingdom, the regulardose vial contains about $100 \mu \mathrm{g}$, which appears to be adequate for postpartum prophylaxis.

Massive fetomaternal haemorrhages of more than $30 \mathrm{~mL}$ of whole blood occur in less than $1 \%$ of deliveries. These massive haemorrhages can lead to immunization if adequate RhIG is not administered. A maternal sample should be obtained within 1 hour of delivery and screened using a test such as the rosette technique for massive feto-maternal haemorrhage. If positive, quantitation of the haemorrhage must be done by Kleihauer-Betke or by flow cytometry. The calculated volume of fetomaternal haemorrhage is then divided by 30 to determine the number of required vials of
RhIG. A simpler way to calculate the dose is to multiply the fetal cell percentage by 50 , which gives the volume of fetomaternal haemorrhage in millilitres. Because the Kleihauer-Betke is an estimate, one vial is added to the calculated answer. If needed, additional vials of RhIG should be administered within 72 hours of delivery or as soon as possible.

\section{Conclusion}

The advancements made in diagnostic as well as therapeutic aspects of HDFN has led to a commendable and steady decline in the overall morbidity and mortality associated with the disease all over the world. With successful implantation of prophylactic RhIG administration, most of the developed countries have been successful in restricting the menace due to Rh Blood Group system and have shifted their focus on HDFN due to other minor blood group antigens. Evolution of platforms like Next Generation Sequencing and Microarray have resulted in a paradigm shift from phenotype to genotype based antigenic determination in complex cases of HDFN. The developing countries are also following the trend and need to implement a cost-effective strategy [28] targeting a larger population for prophylaxis with provision of molecular testing for complex cases.

\section{Bibliography}

1. Izetbegovic S. "Occurrence of $\mathrm{ABO}$ And $\mathrm{RhD}$ Incompatibility with Rh Negative Mothers". Materia Socio Medica 25.4 (2013): 255-258.

2. Mentzer WC. "Louis Diamond and His Contribution To Haematology". British Journal of Haematology 123.3 (2003): 389-395.

3. Orkin SH., et al. "Nathan and Oski's hematology and oncology of infancy and childhood" (2014).

4. Parsons LG. "Haemolytic disease of the newborn". Lancet 1.6451 (1947): 534.

5. Fan J., et al. "Associations of Rhesus and non-Rhesus maternal red blood cell alloimmunization with stillbirth and preterm birth". International Journal of Epidemiology 43.4 (2014): 1123-1131.

6. Hendrickson JE and Delaney M. "Hemolytic disease of the fetus and newborn: modern practice and future investigations". Transfusion Medicine Reviews 30.4 (2016): 159-164.

7. Zipursky A and Paul VK. "The global burden of Rh disease". Archives of Disease in Childhood. Fetal and Neonatal Edition 96.2 (2011): F84-F85.

8. Guideline CP Use THE Immunoglobulin OFA. "Clinical Practice Guideline The Use Of Anti-D Immunoglobin For The Prevention Of Rhd Haemolytic Disease Of The New born The Irish Haematology Society". Institute of Obstetricians and Gynaecologists, Royal College of Physicians of Ireland And Obstetrics an (2014): 13 . 
9. Filbey D., et al. "The prevalence of red cell antibodies in pregnancy correlated to the outcome of the newborn: A 12 year study in central Sweden". Acta Obstetricia et Gynecologica Scandinavica 74.9 (1995):687-692.

10. Howard H., et al. "Consequences for fetus and neonate of maternal red cell allo-immunisation". Arch Dis Childhood-Fetal Neonatal 78.1 (1998): F62-F66.

11. Chandrasekar A., et al. "The clinical outcome of non-RhD antibody affected pregnancies in Northern Ireland". Ulster Medical Society Transactions 70.2 (2001): 89-94.

12. Lee CK., et al. "Prevalence and specificity of clinically significant red cell alloantibodies in Chinese women during pregnancy--a review of cases from 1997 to 2001". Transfusion Medicine 13.4 (2003): 227-231.

13. Gottvall $\mathrm{T}$ and Filbey D. "Alloimmunization in pregnancy during the years 1992-2005 in the central west region of Sweden". Acta Obstetricia et Gynecologica Scandinavica 87.8 (2008): 843-848.

14. Al-Ibrahim. "Red blood cell alloimmunization among Saudi pregnant women in the central province of Saudi Arabia". Kuwait Medical Journal 40: 1-26.

15. Pahuja S., et al. "The prevalence of irregular erythrocyte antibodies among antenatal women in Delhi". Blood Transfuse (2011): 388-393.

16. Roopenian DC and Akilesh S. "FcRn: the neonatal Fc receptor comes of age". Nature Reviews Immunology 7.9 (2007): 715725 .

17. Firan M., et al. "The MHC class I-related receptor, FcRn, plays an essential role in the maternofetal transfer of $\gamma$-globulin in humans". International Immunology 13.8 (2001): 993-1002.

18. Harmening D. "Modern blood banking and amp; transfusion practices". FA Davis (2012): 648.

19. Klein $\mathrm{H}$ and Anstee D. "Mollison's blood transfusion in clinical medicine”. Blackwell Publishing (2008): 93-110.

20. Denise H. "Modern blood banking and transfusion practices". $6^{\text {th }}$ edition (2012): 427-438.

21. Zipursky A., et al. "The Transplacental Passage Of Foetal Red Blood Cells And The Pathogenesis Of Rh Immusisation During Pregnancy". Obstetrical and Gynecological Survey 19.2 (1964):233-235.

22. Bowman JM. "The prevention of Rh immunization". Transfusion Medicine Reviews 2.3 (1988): 129-150.

23. Saran RK. "Transfusion medicine technical manual". DGHS (2003).

24. Judd WJ. "Practice guidelines for prenatal and perinatal immunohematology, revisited". Transfusion 41.11 (2001): 14451452.
25. Finning K., et al. "Fetal genotyping for the K (Kell) and Rh C, c, and $\mathrm{E}$ blood groups on cell-free fetal DNA in maternal plasma". Transfusion 47.11 (2007): 2126-2133.

26. Dubey R., et al. "Validation of Gel Microcolumn Assay for Red Cell Alloantibody Titration by Correlating with Conventional Tube Testing and Clinical Outcome in Rh Negative Antenatal Cases". TRANSFUSION 58 (2018): 190A-190A.

27. Mari G., et al. "Noninvasive diagnosis by Doppler ultrasonography of fetal anemia due to maternal red-cell alloimmunization". The New England Journal of Medicine 342.1 (2000): 9-14

28. Delaney M. "Haemolytic disease of the fetus and newborn: advancements in precision and prevention". International Society of Blood Transfusion 14.1 (2019): 32-36.

\section{Volume 3 Issue 10 October 2019 (C) All rights are reserved by Rounak Dubey., et al.}

